\title{
ESCOLAS BILINGUES PARA SURDOS NO BRASIL: UMA LUTA A SER CONQUISTADA.
}

\author{
ESCUELAS BILINGÜES PARA SORDOS EN BRASIL: UNA LUCHA A SER \\ CONQUISTADA
}

\section{BILINGUAL SCHOOLS FOR DEAF IN BRAZIL: A FIGHT TO BE WON}

\author{
Anaisa Alves de Moura ${ }^{1}$ \\ Edileuza Lima FREIRE ${ }^{2}$ \\ Neudiane Moreira FELIX ${ }^{3}$
}

RESUMO: O presente artigo tem como temática central o desenvolvimento educacional da comunidade surda através de suas lutas e como objetivo geral ressaltar a importância da implantação de escolas bilíngues no Brasil. Tomou-se como embasamento teórico os autores Kyle (1999), Quadros (2009, 2004), Skliar (1997) entre outros. O estudo é de abordagem qualitativa do tipo revisão bibliográfica reflexiva, realizado a partir da leitura e aprofundamento da literatura vigente sobre a temática no período de janeiro a maio de 2017. Os resultados indicam que as instituições escolares devem se adequar em prol da valorização educacional dos surdos, do seu desenvolvimento cognitivo, social e intelectual. Escolas bilíngues priorizam a língua brasileira de sinais (LIBRAS) como a língua primária e o português escrito como língua secundária para os alunos surdos - ao contrário das escolas inclusivas, que incluem os alunos surdos em salas de aulas mistas com alunos ouvintes, na qual a língua primária é o português e a secundária (LIBRAS), onde o interprete se torna o mediador entre o aluno surdo e os demais ouvintes, dificultando a aprendizagem do mesmo. Considera-se que escolas bilíngues são capazes de preparar seus estudantes para a vida através do ensino estruturado, baseado na língua de sinais, a partir do uso das atribuições linguísticas das Libras, facilitando o desenvolvimento e a aprendizagem do aluno surdo em sala de aula.

PALAVRAS-CHAVE: Bilinguismo. LIBRAS (Língua Brasileira de Sinais). Escolas. Educação.

RESUMEN: El presente artículo tiene como temática central el desarrollo educativo de la comunidad sorda a través de sus luchas y como objetivo general resaltar la

1 Centro Universitário INTA (Uninta), Sobral - CE - Brasil. Doutoranda em Ciências da Educação ULHT - Lisboa/Portugal (2017). Atualmente integra um Grupo de Pesquisa do CNPq: Grupo de Estudos e Pesquisas Autobiográficas (GEPAS), da Universidade Estadual Vale do Acaraú. Vinculada a CAPES pelo Programa PARFOR desde 2012 como professora pesquisadora e atua na Educação a Distância UNINTA. E-mail: anaisa1000@ hotmail.com.

2 Centro Universitário INTA (Uninta), Sobral - CE - Brasil. Professora dos cursos na modalidade a distância e presencial. E-mail: edileuza_sbc@yahoo.com.br .

3 Centro Universitário INTA (Uninta), Sobral - CE - Brasil. Professora Pesquisadora II do Plano Nacional de Articulação e Formação de Professor da Educação Básica - PARFOR/UVA/CAPES. Atualmente atua na área de Educação a Distância do UNINTA - Centro Universitário INTA. E-mail: cesecgeral.neudiane@hotmail.com. 
importancia de la implantación de escuelas bilingües en Brasil. Fue asumido como base teórica los autores Kyle (1999), Quadros (2009, 2004), Skliar (1997) entre otros. El estudio es un enfoque cualitativo del tipo de revisión bibliográfica reflexiva, realizado a partir de la lectura y profundización de la literatura actual sobre la temática en el período comprendido entre enero y mayo de 2017. Los resultados indican que las instituciones escolares deben adaptarse a la apreciación educativa de los sordos, su desarrollo cognitivo, social e intelectual. Las escuelas bilingües priorizan la lengua brasileña de señales (LIBRAS) como la lengua primaria y el portugués escrito como lengua secundaria para los alumnos sordos. Avesso de las escuelas inclusivas, que incluyen a los alumnos sordos en aulas mixtas con alumnos oyentes, en la que la lengua primaria es el portugués y la secundaria (LIBRAS), donde el interprete se convierte en el mediador entre el alumno sordo y los demás oyentes que dificulta el aprendizaje del mismo. Se considera que las escuelas bilingües son capaces de preparar a sus estudiantes para la vida a través de una educación estructurada, basada en el lenguaje de las señales, desde el uso de las asignaciones lingüísticas de las libras, facilitando el desarrollo y aprendizaje del alumno sordo en el aula.

PALABRAS CLAVE: Bilingüismo, LIBRAS (Lengua Brasileña de Señales), Escuelas y Educación.

ABSTRACT: This paper has the educational development of deaf community as main subject through its fights and as main objective to emphasize the importance of bilingual schools installation in Brazil. Theoretical background has been took from authors like Kyle (1999), Quadros (2009, 2004), Skliar (1997) and others. This study is a qualitative approach like a reflexive literature review, made since of readings and deepening in current literature about the theme, between January and May 2017. Results show that scholar institutions must adapt themselves in order to increase the educational valorization of the deaf, to increase their cognitive, social and intellectual development. Bilingual schools prioritize the Brazilian Sign Language (BSL) as primary language and the written Portuguese as the second language to the deaf students. Unlike the inclusive schools that insert deaf students among listeners students in a mixed classroom where the primary language is the Portuguese and the second one is $B S L$, and the interpreter becomes the mediator between the deaf student and the others, hindering the learning of the deaf. It is considered that bilingual schools are able to prepare their students to life through structured teaching based on the sign language, from the use of the language properties of the BSL, facilitating the development and learning of the deaf student in the classroom.

KEYWORDS: Bilingualism. LIBRAS (Brazilian sign language). Schools. Education.

\section{Introdução}

Estamos vivenciando no Brasil o progresso da educação para surdos, no que diz respeito ao acolhimento destes dentro de salas de ensino regular. Para isto, as escolas inclusivas têm tido como objetivo incluir o aluno com deficiência no ambiente escolar 
com crianças ouvintes, dando-lhes oportunidade de relacionar-se com a sociedade e desenvolverem-se na educação. Mas no caso do deficiente auditivo, este sistema inclusivo deixa a desejar, pois as políticas públicas da educação inclusiva não visam o aperfeiçoamento e o possível desenvolvimento dos alunos surdos, os quais não estão aprendendo em sua própria língua que é a Língua Brasileiras de Sinais - LIBRAS.

Os surdos vêm participando do ensino-aprendizagem em salas de aulas junto com alunos ouvintes, que aprendem em sua própria língua (o português), enquanto que o aluno surdo necessita de um intérprete para auxiliá-lo no repasse de conhecimento transmitido e lecionado pelo professor regente em sala de aula.

Sabe-se que o papel do intérprete é apenas repassar informações entre aluno/professor e vice/versa, ele não pode interferir no ensino diretamente. A ética trabalhista deste profissional o impossibilita de fazer qualquer interferência no aprendizado do aluno. Por isso a necessidade de professores bilíngues e escolas especializadas. De acordo com Sá (2002, p.65-66):

Incluir surdos em salas de aula regulares inviabiliza o desejo dos surdos de construir saberes, identidades e culturas a partir das duas línguas (a de sinais e a língua oficial de seu país) e impossibilita a consolidação linguística dos alunos surdos.

O ideal é que o aluno surdo inserido em sala de aula de ensino aprenda com mais eficácia em sua própria língua, todavia, no caso da inclusão, os conteúdos lhes são repassado por meio de um intérprete que atua interpretando/traduzindo do português para LIBRAS e vice/versa, ou seja, ele aprende de uma forma secundária e não primária como lhe é garantido por direito na Lei da Acessibilidade lei 10.098 de 10 de Dezembro de 2000, a qual determina que o aluno surdo se desenvolva dentro de suas habilidades linguísticas. E o seu Decreto no 5.626 de 22 de Dezembro de 2005, que assegura a ampliação da educação para o aluno surdo dentro dos parâmetros linguísticos, e especifica o preparo profissional do educador, e a difusão da libras nas escolas e suas especificidades.

Tendo como base a Lei de Libras e seu Decreto, a luta desta comunidade continua; eles almejam que sejam implantadas escolas bilíngues no Brasil, na perspectiva que seus direitos sejam respeitados, e a reivindicação principal é que os mesmos possam desenvolver-se em sua própria língua. Sobre isto Lacerda (1996 p. 79 apud. Silva; NEMBRI, 2003, p. 26) assevera que: 
No Brasil, como em muitos outros países, a experiência com educação bilíngue ainda se encontra restrita. Um dos motivos para este quadro é, sem dúvida, a resistência de muitos a considerar a língua de sinais como uma língua verdadeira ou aceitar a sua adequação ao trabalho com o surdo.

Não somente no Brasil, mas em muitos países, não se tem ponderado que a língua de sinais seja o meio de comunicação eficaz para o desenvolvimento dos portadores de necessidades especial auditiva. O ideal, para que uma escola funcione bem, é respeitar os direitos que o aluno surdo tem de aprender e receber conhecimentos em sua própria língua, tendo como professor, um ser capacitado para estar em sala de aula atuando e lecionando seus conteúdos em LIBRAS, facilitando assim a transmissão de conhecimentos, trazendo desenvolvimento e capacitações para o aluno surdo.

É importante dar à eles a oportunidade de estruturar seus pensamentos, desenvolver suas habilidades linguísticas, dinamizar seus conhecimentos - e isso só acontecerá se considerarmos a sua língua como parte principal na educação. Vale a pena salientar o pensamento de Brito (1993, p.87-88) quando afirma a importância da língua de sinais para o aprendizado dos surdos:

\begin{abstract}
Além da função comunicativa, as línguas naturais têm a importante função que é a de suporte linguístico para a estruturação do pensamento. Esta última, frequentemente é ignorada por especialistas envolvidos na educação do surdo que consideram a língua apenas como meio de comunicação. [...] As Línguas de Sinais, por serem naturais e de fácil acesso para os surdos, são extremamente importantes para o preenchimento da função cognitiva e suporte do pensamento.
\end{abstract}

Embasado nessas informações, deve-se indagar se existem escolas bilíngues funcionando no Brasil, ou se apenas estão incluindo o aluno em salas de aulas mistas de ouvintes no ensino regular, sem repensar no nível de desenvolvimento destes alunos. As escolas de ensino regular devem priorizar a língua dos seus alunos, seja ela portuguesa ou LIBRAS, na verdade, deve-se mensurar o conhecimento a partir da língua utilizada pelo determinado ser, seja ele ouvinte ou surdo.

\title{
A história da educação dos surdos e suas lutas
}

A história nos mostra que muitos surdos foram excluídos da educação simplesmente por não possuírem uma fala, revelando-nos que, para os ouvintes, o 
problema maior não era a surdez, propriamente dita, mas sim a falta de uma fala. Existem ainda pessoas ouvintes que confundem a habilidade de falar através da voz, com a inteligência de determinada pessoa, talvez seja porque a palavra "fala" esteja etimologicamente ligada ao verbo/pensamento/ação e não ao simples ato de emitir sons articulados.

Por isso, até o fim do século XV, não haviam escolas especializadas para surdos na Europa, porque, naquela época, os surdos eram considerados incapazes de serem instruídos, por não possuírem uma língua oral. Por consequência deste pensamento, as pessoas surdas foram excluídas da sociedade e muitos tiveram sua sobrevivência prejudicada. Existiam leis que vedavam os surdos de quaisquer direitos sociais, eram proibidos de possuir ou herdar propriedades, casar-se, e votar como os demais cidadãos.

Algumas pessoas, como os monges beneditinos, começaram a ensinar os surdos através do método do oralismo, desenvolvendo a língua oral de seus pais, outros ensinavam através da língua escrita e sinais, ainda outros usavam a língua de sinais, treinamento da voz e leitura de lábios. Entre essas pessoas que começaram a educar os surdos, alguns acreditaram que a primeira etapa para a educação deles seria a língua falada adotando uma metodologia chamada "oralismo puro". Outros utilizaram a língua de sinais, já conhecida pelos alunos, como meio para o ensino da fala, foi o chamado método combinado.

A partir do século XVI o monge francês chamado Charles Michel de L’Épeé interessou-se pelos surdos, unindo-se à eles que perambulavam pelas ruas e praças da cidade. Ele juntou-se aos surdos com a finalidade de aprender a língua de sinais utilizada por eles na rua, seu objetivo era ajudá-los através de sua língua. Ele organizou uma escola para surdos em sua própria casa, na qual foram matriculados setenta e cinco alunos, desenvolveu um método de ensino, uma mistura de língua de sinais e a língua francesa. Foi um grande mestre da educação dos surdos e tornou-se famoso através de seus métodos de ensino, fundou uma escola em sua própria casa e passou a educar os surdos que encontrava pelas praças e ruas da França, também organizou a primeira escola para professores de surdos.

Foi um dos grandes responsáveis pela língua de sinais brasileira, pois através de seu instituto na França, veio para o Brasil o padre Huet, um professor surdo que a convite de D. Pedro II, veio ao Brasil trazendo consigo o "método combinado" criado 
por L'Épeé para trabalhar a educação de surdos na França, no qual foi utilizado aqui no Brasil.

A primeira escola fundada para surdos no Brasil foi fundada em 1857, no Rio de Janeiro; o Instituto Nacional da Educação de Surdos (INES). A partir da criação deste Instituto, a língua de sinais brasileira foi desenvolvida através da mistura da língua de sinais francesa, trazida por Huet em 1871. Esta escola já possuía alunos vindos de várias partes do Brasil, que ao completarem 18 anos, retornavam às cidades de origem levando com eles a LIBRAS.

Os poderes públicos voltados à educação especial deveriam voltar seus olhares para as reivindicações da comunidade surda brasileira, que buscam uma educação de qualidade. Esta busca requer uma escola de qualidade, que atenda suas necessidades e os capacitem à uma educação, na qual professores e intérpretes sejam profissionais conhecedores da língua de sinais, sua estrutura e gramática. Embasado na Lei da Acessibilidade, Lei da Libras e seu Decreto os quais permitiu-lhes obter conhecimentos em sua língua fonte, Quadros (2009, p.156) destaca que:

Os movimentos surdos clamam por inclusão em outra perspectiva. Nota-se que eles entendem a inclusão como garantia dos direitos de terem acesso à educação de fato, consolidada em princípios pedagógicos que estejam adequados aos surdos. As proposições ultrapassam as questões linguísticas, incluindo aspectos sociais, culturais, políticos e educacionais.

\section{A importância das escolas bilíngues na educação dos surdos}

Para que os alunos surdos se desenvolvam efetivamente nas escolas é necessário entender como eles aprendem, conhecer sua cultura e respeitá-la, apreciar sua língua, e tê-la como principal meio de interação e comunicação.

Para Jokinen (1999) o desenvolvimento da criança surda está ligado à sua língua, por isso há a necessidade de uma interação desde a infância com relação à sua língua, principalmente na educação, ou seja, o desenvolvimento escolar dos surdos só ocorrerá de forma efetiva se a língua de sinais, que no Brasil é a LIBRAS, for aceita como primeira língua ou língua materna. $\mathrm{O}$ autor explica que na filosofia educacional bilíngue aplicada à Educação de Surdos, a língua falada no país é ensinada como segunda língua na modalidade escrita e, caso o aluno quiser, na modalidade oral. Kyle (1999) defende essa ideia propondo que toda criança surda deveria ter um ensino bilíngue. 
É de extrema importância que se construam escolas bilíngues voltadas à educação, sabendo-se que é essencial para o próprio desenvolvimento da pessoa surda, para que aprenda através da língua usada e falada por seus iguais e por aqueles que se identificam com a comunidade, no caso; familiares, amigos e interpretes.

No decorrer da história educacional voltada para estes alunos, foram utilizados vários métodos educacionais tais como: alfabeto manual, oralismo, comunicação total, gestualismo, bilinguismo, entre outros. Entretanto, verificou-se não haver um avanço ou progresso na educação dos surdos, e essa descoberta nos remete a uma reflexão: Por que os surdos não se desenvolveram como deveriam? A inclusão tem funcionado? Precisamos refletir sobre uma nova filosofia educacional envolvendo as duas línguas principais do nosso país (LIBRAS e o Português) sem inverter a ordem. No caso do surdo, sua língua primária sendo LIBRAS e o Português escrito secundária, esta reflexão nos remete ao bilinguismo propriamente dito.

Dentro da estrutura educacional, deve-se dar a devida importância para as escolas bilíngues, as quais proporcionam o respeito e a dignidade da comunidade surda, sua cultura, sua língua, sua maneira de aprender. Levando em consideração os fatos históricos, percebe-se que o surdo aprende diferente do ouvinte, pois neste caso o aluno tem um sentido mais aguçado que é a visão, ele precisa de materiais visuais para assimilar o conteúdo, por isso o uso da língua de sinais é essencial na transmissão de conhecimentos. Anelando o desenvolvimento e um verdadeiro aprendizado, o bilinguismo deve ser implantado nas escolas, que precisam ser especializadas para receber estes alunos e ensiná-los em sua própria língua.

A reivindicação por escolas bilíngues vem sendo ouvida, pois algumas escolas estão se engajando no processo de desenvolvimento para receberem alunos surdos, possibilitando o aprendizado à esse através do bilinguismo. No entanto, falta muito a ser conquistado, se analisarmos do ponto de vista das contribuições referentes a uma educação de qualidade.

\section{Contribuições das escolas bilíngues para a comunidade surda}

Certamente são inúmeras as contribuições que as escolas bilíngues trarão para a comunidade surda no Brasil, entre elas seu desenvolvimento escolar, social e psicológico. O ensino em LIBRAS garante ao aluno surdo seu aprendizado, respeito a sua cultura e a desenvoltura de suas habilidades. 
Promove ainda o respeito à essa comunidade, motivada por um conhecimento aprofundado de sua língua, a qual é a forma de expressão de seus usuários. É através dela que se consegue expor seu ponto de vista, pensamentos, conhecimentos e habilidades. Por isso a insistência dos surdos por escolas bilíngues. Conforme Skliar (1997, p.144) o modelo bilíngue tem como objetivo criar uma identidade bicultural na criança surda quando afirma que:

O objetivo do modelo bilíngue é criar uma identidade bi cultural, pois permite à criança surda desenvolver suas potencialidades dentro da cultura surda e aproximar-se, através dela, à cultura ouvinte. Este modelo considera, pois, a necessidade de incluir duas línguas e duas culturas dentro da escola em dois contextos diferenciados, ou seja, com representantes de ambas as comunidades desempenhando na aula papéis pedagógicos diferentes.

Não podemos subestimar alguém ou uma comunidade pela sua forma de comunicar, é preciso engajar-nos conjuntamente para que haja uma compreensão mútua, desenvoltura e apreciação por ambas as partes. Certamente, essa luta por escolas bilíngues no Brasil não deve ficar apenas no papel ou em protestos da comunidade surda. Deve tornar-se uma grande realidade, com contribuições e possibilidades do surdo de se tornar independente, vivenciando sua cultura dentro do ambiente escolar.

Consideremos a importância da língua de sinais, pois a mesma deve ser ensinada desde a infância para que o aprendizado e desenvolvimento intelectual de uma criança surda, seja desenvolvida e baseada na estrutura linguística de sua língua. Entendemos que há uma barreira a ser vencida entre surdos e ouvintes para uma efetiva comunicação: a língua, a qual não só favorece a comunicação entre todos, mas principalmente a aquisição do conhecimento e interação.

Segundo o Decreto $\mathrm{n}^{\mathrm{o}} 5.626 / 05$, o qual deixa bem claro, no seu artigo 14, capítulo IV, inciso II: ofertar obrigatoriamente, desde a educação infantil, o ensino da Libras e também da Língua Portuguesa, como segunda língua para alunos surdos; assim como no inciso V: apoiar, na comunidade escolar, o uso e a difusão de Libras entre professores, alunos, funcionários, direção da escola e familiares, inclusive por meio da oferta de cursos.

É necessário conhecermos as leis do nosso país, pois elas embasam nossas reivindicações e nos garantem conquistas que nos possibilita sermos ouvidos por nossos 
governantes e responsáveis por nossa educação. Além disso, nos respalda e nos protege legalmente à promovermos lutas por melhorias educacionais e sociais.

\section{Material e método}

Foi realizada uma pesquisa bibliográfica cujo objetivo é mostrar que desde a origem do homem o surdo existe e nessa existência destacou-se o isolamento, o preconceito que lhes eram impostos e também as pessoas que lutavam para reconhecer o surdo como ser humano capaz e prestativo à sociedade. Partindo desse reconhecimento das filosofias educacionais; oralismo, comunicação total, bilíngue e LIBRAS - Língua Brasileira de Sinais são formas de comunicação entre o ouvinte e o surdo.

Uma luta a ser conquistada, onde se inicia em projetos e palavras bonitas, mas que não passa disso. Ressaltados em estudos, pesquisas e vivências que mostram a inclusão dos alunos surdos nas escolas regulares como a melhor opção para alfabetização, ou seja, dão aquele velho jeitinho Brasileiro, de incluir, porém de uma forma camuflada que está mais para 'exclusão', pois com a falta de escolas especializadas, o ensino na maioria das vezes nunca é exercido de forma correta.

As escolas que acolhem o surdo em sala regular de ensino têm como finalidade promover sua participação num contexto social ampliado, para assim garantir igualdade tanto social como educacional, permitindo um contato mais direto com a linguagem oral. Os alunos ouvintes e os surdos precisam ser estimulados e motivados a se tornarem comunicativos entre si.

As instituições de ensino têm a obrigatoriedade de sempre que necessário evidenciar que a criança surda é importante e que primeiramente ela terá que aprender sua língua materna a LIBRAS, para depois estar apta para adquirir a bilíngue e a língua portuguesa escrita e falada. Visando sempre que não será uma tarefa fácil, mas que dependerá do seu desempenho e muita força de vontade.

As escolas podem ser um dos fatores provedores de integração ou desintegração das comunidades surdas. Dependendo da metodologia adotada, poderão alcançar o avanço necessário para a real integração e desenvolvimento intelectual e social dos surdos. Se uma escola rejeita a língua de sinais, as crianças surdas que estudam nesta escola, não vão conhecer a comunidade surda de sua cidade e, consequentemente, não aprenderão uma língua de sinais. Estudos e pesquisas 
comprovam que o surdo aprende, comunica-se e desenvolve-se através da própria língua deles.

Sabe-se que é através do uso de sua língua que haverá compreensão e um desenvolvimento da sua aprendizagem. Por causa dessa falta de linguagem própria, o surdo perde o interesse de frequentar a escola, alguns desistem por falta de compreensão da língua falada em sala de aula, e entre eles há um grande índice de analfabetismo.

Esta linguagem é capaz de conduzi-los ao conhecimento e desenvoltura educacional. Isso só acontece quando se reconhece sua língua e a utiliza como meio principal da comunicação e transmissão de conhecimentos. Por esta razão, os surdos vêm lutando por escolas bilíngues.

\section{Análise dos resultados}

Percebe-se que diante do que foi relatado existe a necessidade de respeitar e compreender o surdo, ampliando-lhe o direito de oportunidades educacionais, ligadas ao objetivo de igualdade. Devemos nos conscientizar dessa necessidade primária do surdo que é o uso de LIBRAS, sua língua primária dentro do ambiente educacional e mantermos, e da sensibilidade para com esses alunos, dando-lhes o suporte escolar educacional voltando-se às suas necessidades, respeitando sua cultura, facilitando sua cidadania, pois são indivíduos da nossa sociedade que possuem sua própria cultura e identidade.

É possível nos conscientizarmos que é através da língua/gestual que eles poderão se expressar com real aprendizado, compreensão e desenvolvimento. Todos os seres necessitam de uma língua para se comunicar e com os surdos não é diferente. É através de LIBRAS que o surdo expressa seus pensamentos, emoções e cultura. A partir do conhecimento sobre a legislação e, especificamente, sobre o reconhecimento da LIBRAS, a família, bem como os professores, podem começar a exigir mudanças na escola, a fim de atender as necessidades educacionais especiais do aluno com surdez para que a inclusão possa de fato ocorrer para esses alunos.

\section{Considerações finais}

A história educacional do surdo reflete um total descaso e desrespeito ao ser humano, os quais por anos sofreram descrenças, foram desacreditados, privados dos 
direitos sociais, maltratados e impossibilitados de possuírem uma educação de qualidade. Eles não se deixaram abater por determinados acontecimentos. Lutaram e continuam buscando um reconhecimento de sua cultura, sua língua, sua comunidade e por uma educação de qualidade que lhes garanta autonomia.

A Língua Brasileira de Sinais, língua oficial da comunidade surda brasileira, tem aberto o caminho para um novo olhar educacional tanto por parte dos surdos quanto pelos seus educadores.

Diante desta afirmativa, vimos que a língua de sinais é a maior responsável pelo aprendizado, desenvolvimento e avanço da comunidade surda brasileira, capaz de produzir todos os conhecimentos e interações com o mundo, e isso envolve a educação. Então, cabe às autoridades da educação rever e elaborar projetos para que muitas escolas bilíngues sejam implantadas em nosso país, favorecendo assim tanto a comunidade surda brasileira quanto a sociedade que é formada por cidadãos diferentes.

Não existe comunicação sem libras para os surdos, é como o português para o ouvinte, é essencial, pois a comunicação nos garante liberdade, avanço e desenvolvimento. Não há comunicação sem linguagem, não há ensino sem comunicação, não há aprendizado sem compreensão, não há compreensão sem entendimento, por isso a necessidade de escolas bilíngues no Brasil em funcionamento ativo nas redes de ensino do país.

Considerando todas as informações mencionadas descobrimos que a comunidade surda brasileira vem rompendo barreiras e através do uso de sua língua tem alcançado vitórias, mesmo que em meio a muitas lutas, seus espaços estão sendo conquistados. Podemos destacar a implantação de escolas bilíngues em algumas capitais como São Paulo, as Escolas Municipais de Educação Bilíngue para Surdos - EMEBS e Unidades Polo de Educação Bilíngue para Surdos que se destinam às crianças, adolescentes, jovens e adultos com surdez, com surdez associada a outras deficiências, limitações, condições ou disfunções, e surdo cegueira na Educação Infantil e Ensino Fundamental. Em Fortaleza temos a Escola Municipal Francisco Suderland Bastos Mota que já está em funcionamento desde 2016 e atende crianças surdas e ouvintes bem como seus familiares.

O ensino da Língua Brasileira de Sinais é o diferencial da escola. Citamos alguns exemplos apenas como referências, acreditando no sonho pela implantação de mais escolas bilíngues que atendam a demanda e as necessidades da comunidade surda, 
um desafio a ser conquistado em um futuro promissor bilíngue, amparando os surdos nos âmbitos educacionais e sociais.

\section{REFERÊNCIAS}

BRASIL. Decreto n. 5.626, de 22 de dezembro de 2005. Regulamenta a lei de acessibilidade, $\mathrm{n}^{\circ}$ 10.098/2000 e a lei de libras, $\mathrm{n}^{\circ}$ 10.426. Diário Oficial da República Federativa do Brasil. Brasília, 22 dez. 2005.

BRITO, L. F. Integração social \& educação de surdos. Rio de Janeiro: Babel, 1993.

JOKINEN, M. Alguns pontos de vista sobre a educação dos surdos nos países nórdicos. In: SKLIAR, Carlos (Org.). Atualidade da Educação Bilíngue para Surdos. Processos e projetos pedagógicos. Vol. 1. Porto Alegre: Mediação, 1999.

KYLE, J. O ambiente bilíngue: alguns comentários sobre o desenvolvimento do bilinguismo para os surdos. In: SKLIAR, Carlos (Org.). Atualidade da Educação Bilíngue para Surdos. Processos e projetos pedagógicos. Vol. 1. Porto Alegre: Mediação, 1999.

LACERDA, C. B. F. Os Processos Dialógicos entre Aluno Surdo e Educador Ouvinte: Examinando a Construção de Conhecimentos. Tese de Doutorado, UNICAMP: Campinas/ São Paulo, p.79, 1996.

QUADROS, R. M. de. Alfabetização e o ensino da língua de sinais. Textura, Canoas n.3 p.54, 2004.

QUADROS, R. M. de (Org.). STUMPF, Marianne Rossi et al. Estudos surdos IV. Petrópolis, RJ: Arara Azul, 2009.

SÁ, N. R. L. de. Cultura, Poder e Educação de Surdos. Manaus: Editora da Universidade Federal do Amazonas, 2002.

SKLIAR, C. (Org). A educação para os Surdos entre a Pedagogia Especial e as Políticas para as Diferenças. In: Desafios e Possibilidades na Educação Bilíngue para Surdos. SEE/ INES. Rio de Janeiro: INES, 1997b.

SKLIAR, C. Uma perspectiva sócio-histórica sobre a psicologia e a educação dos surdos. In (org) Educação e exclusão: abordagens sócio antropológicas em educação especial. Porto Alegre: Editora Mediação, 1997. 


\section{Como referenciar este artigo}

MOURA Anaisa Alves de.; FREIRE, Edileuza Lima.; FELIX, Neudiane Moreira. Escolas Bilingues para surdos no Brasil: uma luta a ser conquistada. Revista on line de Política e Gestão Educacional, Araraquara, v.21, n. esp.2, p. 1283-1295, nov. 2017. Disponível em: <http://dx.doi.org/10.22633/rpge.v21.n.esp2.2017.10172>. ISSN: 15199029.

Submetido em: 30/07/2017

Aprovado em: 20/08/2017 